\title{
How Public Health Agencies Use the Public Health Emergency Preparedness Capabilities
}

\author{
Jennifer Horney, PhD (1); Eric G. Carbone, PhD, MBA; Molly Lynch, MPH; \\ Cheng Shuang Ji, PhD; Terrance Jones, MPH
}

$\mathrm{I}$ n March 2011, the Centers for Disease Control and Prevention (CDC) published 15 public health preparedness (PHP) capabilities to serve as national PHP standards. ${ }^{1}$ The capabilities provided state, tribal, local, and territorial (STLT) public health departments with a framework for organizing their preparedness activities, setting priorities, and dedicating resources to build or sustain the capabilities. Preparedness activities are supported by the Public Health Emergency Preparedness (PHEP) Cooperative Agreement, which provides federal funding to 62 STLT public health departments to develop and maintain their ability to effectively respond to public health threats. Although variations across public health emergency responses have made it difficult to standardize evaluation or assess costeffectiveness of PHP programs, in general, the development of the capabilities provided awardees a roadmap of recommended functions and tasks that were supported by a variety of required resource elements and closely linked to annual funding guidance.

An online survey was developed in collaboration with the CDC's Office of Public Health Preparedness and Response (now the Center for Preparedness and Response) to assess awardee use of the capabilities. ${ }^{2}$ Forty-eight of 62 (77\%) STLT PHEP directors completed the survey between September and November 2015. Awardees most frequently used the capabilities for 3 activities: training (57.9\%), exercises (55.1\%), and evaluation $(62.1 \%)$. Specifically, more than twothirds of awardees reported using 4 capabilities in the development of training, exercises, and for evaluating program activities: emergency operations coordination (Capability 3; 77.1\%, 79.2\%, and 70.8\%, respectively), medical countermeasure dispensing (Capability 8; $72.9 \%, 75.0 \%$, and $68.8 \%$, respectively), medical material management and distribution (Capability 9; $68.8 \%, 75.0 \%$, and $72.9 \%$, respectively), and volunteer management (Capability 15; 66.7\%, 68.8\%, and 68.8\%, respectively).

Since 2002, more than US $\$ 9$ billion in federal funding have been provided by the CDC to STLT health departments for PHP activities, including improving disease surveillance and laboratory systems and responding to events such as pandemic influenza, Ebola virus disease, and Zika virus. The development of the capabilities in 2011 and their revision in 2018 was an attempt to improve planning and resource allocation, as well as to address the challenges of evaluating the use and value of the funds invested to the nation's ability to prepare for and respond to public health threats. Several 2018 updates directly addressed the 4 capabilities that this study found were most highly used by awardees for training, exercises, and evaluation, including clarifying jurisdictional public health agency lead or support roles based on incident characteristics, updates to vaccine administration and coordination of infectious disease responses, and additional considerations for protecting the safety of emergency responders and volunteers. ${ }^{3}$ While the 2018 revision of the capabilities reflects lessons learned and feedback from preparedness science, practitioners, and associated federal agencies and professional associations, as well as emerging topics such as pandemic influenza and environmental health, it does so based on a model of "everyday use" in activities like training, exercising, and evaluation. ${ }^{4}$

\section{About the Authors}

Epidemiology, University of Delaware, College of Health Sciences, Newark, DE (Dr Horney); Office of Applied Research, Center for Preparedness and Response, Centers for Disease Control and Prevention, Atlanta, GA (Dr Carbone); Center for Communication Science, RTI International, Durham, NC (Ms Lynch); Avar Consulting, Rockville, MD (Dr Ji) and US Public Health Service, Division of State and Local Readiness, Center for Preparedness and Response, Centers for Disease Control and Prevention, Atlanta, GA (Mr Jones).

Correspondence and reprint requests to Jennifer Horney, Epidemiology, University of Delaware, College of Health Sciences, 100 Discovery Blvd, Newark,DE 19713 (e-mail: horney@udel.edu).

\section{Acknowledgments}

This publication was supported by Contract SOO-2014-N-16618 from the US Centers for Disease Control and Prevention (CDC). The opinions expressed in this letter to the editor are those of the authors and do not necessarily represent the official position of the Centers for Disease Control and Prevention. 


\section{REFERENCES}

1. Centers for Disease Control and Prevention, Office of Public Health Preparedness and Response. Public health preparedness capabilities: national standards for state and local planning. March 21, 2011. http://www.cdc.gov/ phpr/capabilities/DSLR_capabilities_July.pdf. Accessed January 25, 2019.

2. Horney JA, Carbone EG, Lynch M, et al. How health department contextual factors affect public health preparedness (PHP) and perceptions of the 15 PHP capabilities. Am J Public Health. 2017;107(S2): S153-160.
3. Centers for Disease Control and Prevention, Office of Public Health Preparedness and Response. 2018 Update initiative: what changed? October 2018. https://www.cdc.gov/cpr/readiness/capabilities-change.htm. Accessed May 18, 2019.

4. Centers for Disease Control and Prevention, Center for Preparedness and Response. Public health emergency preparedness and response capabilities: national standards for state, local, tribal, and territorial public health. January 2019. https://www.cdc.gov/cpr/readiness/00_docs/CDC_Preparednes ResponseCapabilities_October2018_Final_508.pdf. Accessed October 16, 2019. 